\title{
The use of Ontologies in the Development of a Mobile E-Learning Application in the Process of Staff Adaptation
}

\author{
Bakanova A., Letov N.E., Kaibassova D., Kuzmin K.S., Loginov K.V., Shikov A.N.
}

\begin{abstract}
The article discusses the method of using ontologies for developing a mobile application of the corporate e-learning system in the process of adaptation of companies' new employees. The problems of shortening the period of adaptation of newly recruited employees force companies to look for effective methods of personnel management, their training and development. Well-known publications and the best developments in the field of mobile devices in corporate training systems, which allow to determine the vector of development of corporate training systems from e-learning to mobile learning, were considered. The widespread use of mobile devices makes the process of learning and adaptation of employees flexible, convenient, which leads to reduction of the time for employees to join the company's business processes. The problems of motivation and staff engagement in the process of early adaptation remain, but they are solved in the course of our other studies. The original method is use of ontologies when building individual learning paths in the process of adaptation of employees. The article examines the main approaches to the presentation and analysis of employees' competencies based on ontologies when building modern corporate systems of adaptation and personnel training. An original approach to creating mobile applications is proposed, which reduces the time for adaptation and training of new employees.
\end{abstract}

Index Terms: ontologies, corporate knowledge, competencies, competence management, corporate knowledge base, corporate training, mobile application, staff adaptation.

\section{INTRODUCTION}

The costs associated with the selection of new employees, introduction to the subject area, adaptation and training of the specifics of the work and corporate standards that the company incurs in such cases are considerably high. A relatively high turnover rate negatively affects the loyalty of applicants to the company, which reduces the likelihood of hiring highly qualified professionals. For this reason, employee turnover rates are included in HR benchmarking. According to statistics, approximately $80 \%$ of all the dismissals initiated by the workers themselves fall on the first

Revised Manuscript Received on September 25, 2019

Bakanova A., Postgraduate, ITMO University, Saint Petersburg, Russia Letov N.E., Master's Degree, ITMO University, Saint Petersburg, Russia. Kaibassova D., Postgraduate, Eurasian National University L N Gumilev (ENU), Astana, Kazakhstan

Kuzmin K.S., Master's Degree, ITMO University, Saint Petersburg, Russia.

Loginov K.V., postgraduate, ITMO University, Saint Petersburg, Russia.

Shikov A.N., Candidate of Engineering Sciences, Associate Professor, ITMO University, Saint Petersburg, Russia. days and weeks of work at the new place. In order to ensure comfortable conditions for the start of work of new employees, corporate programs for the adaptation and training of personnel are being created.

The concept of personnel adaptation can be defined "as a process in the course of which the new employee is adapted to the diverse aspects of the organization's activities: content and working conditions, corporate culture, internal work rules and mechanisms for working activities" [1]. Analyzing the existing approaches to the organization of personnel adaptation process such as mentoring, Job Shadowing, Budding, we can conclude that the main disadvantage of all these methods is the use of human resources of experienced employees who have to spend additional time of their work time supporting newcomers and switching between the contexts of their tasks and tasks of the new employees. Automation of the staff adaptation process carried out with the help of TMS - Talent Management System [2] will minimize the time spent by experienced staff on supervising newcomers, as well as shorten the time for new employees to enter the real work.

One of the main tasks of staff adaptation is the task of primary education. TMS should allow flexible building of the trajectories of employee training depending on certain criteria: position, grade, specific department, working group, project specifics, existing knowledge and skills of a new employee. One of the ways to personalize training is to focus on the employee competency matrix. Competence is considered as the ability of a specialist (employee) to solve a certain class of professional tasks. Differentiation of the level of competence allows you to assess and monitor the progress of mastering these competencies. In turn, the competency matrix should be defined as a list of competencies that have value for the company and help in the implementation of its tasks, that covers a variety of knowledge, skills, and individual and personal characteristics.

A targeted individual "portrait of skills" of an employee after going through the adaptation process may consist of the form of a profile of competences - a set of competencies and level of knowledge of those that are necessary for the successful implementation of specific tasks. Thus, based on the analysis of the difference in the values of competence levels defined in the competence profile of this position and the current profile of the new employee, individual trajectories of corporate 
training are formed as part of the adaptation process. The implementation of a flexible approach to the formation of individual learning paths lies in the possibility of dynamically changing the path based on a permanent automatic analysis of the speed of the learning process, identifying any issues that might appear. In accordance with the analysis, an employee can be assigned to take additional training modules or reduce their number in order to minimize the time of training and improve the quality of this training.

To implement the automatic formation of individual training paths for new staff, an organized structure of training courses and modules is required. Differentiated assessment of the passage of these courses and modules determines the degree of change in the level of knowledge in the set of competencies, which brings the employee to the target competency profile of the position he applies for after going through the adaptation process.

For these purposes, ontologies are offered, which allow to structure not just the basic terms and concepts, but also training courses for their presentation to students on mobile devices. Corporate training using mobile applications is one of the most popular types of training organization. There is a lot of research in this area and they continue to find new efficient ways to manage the training of personnel, their training, adaptation and development.

\section{Materials AND MeTHODS}

The most striking solutions and research results with positive results are presented by the authors in $[6,7]$, who proposed the OntoAdapt ontology and the EduAdapt architectural model for adapting learning objects taking into account the characteristics of a mobile device, learning style and other contextual information: «We evaluate this proposal in two ways. Firstly, we used scenarios and metrics to assess the ontology. Secondly, we developed a prototype of EduAdapt model and submitted to a class of 20 students with the intention of evaluating the usability and adherence to adapted objects, resulting in a 78 $\%$ of acceptance. In brief, the evaluation presented encouraging results, indicating that the proposed model would be useful in the learning process» [6]. «We believe that the strengths of virtual learning systems, targeted at mobile devices, can be improved by mingling context awareness with content adaptation. The context awareness is formed by data regarding users and their surroundings, such as location data, learning objective, knowledge history and preferences, among others. Content adaptation, accordingly, can personalize the learning object to meet this context. For example, consider the following scenario: a learner, driving her car to the University, may need information regarding the course in which she will have an examination in a few minutes. An application in her mobile phone, using context awareness, can suggest a learning object related to the examination» [7]. The process of student adaptation is also of great importance: «The adaptation process starts in the client, by gathering the current learning context. This information consists of the device characteristics, including the device model, the battery level, available storage capacity, screen size and operating system version. This information is useful to choose de appropriate LO according to devices limitations, such as screen size and multimedia capabilities. Besides these characteristics, the client sends information regarding the connection: network signal strength and type of connection $(3 \mathrm{G}, 4 \mathrm{G}, \mathrm{WiFi}$, etc.). Finally, there is a group of data related to the user, including whether the user is stationary or in movement and the current location» [7].

A new approach using ontologies and knowledge modeling to support the analysis of accessibility and assessment of trainees with various limitations of physical capabilities is described in [8]. «With the obtained results, you can provide knowledge and indicate what disabilities are favoring each of the HTML documents and therefore, the learning object in general, as well as what disabilities are affecting, giving the possibility to correct the accessibility errors for the affected disabilities. In this way, by correcting these errors, the learning object will be accessible for most disabilities, or, better yet, for all disabilities, and all thanks to the information provided by the ontological network, depending on the performed SPARQL query. Making use of the aspects indicated above can generate knowledge of the accessibility of web content for different disabilities, the same that is captured through an ontological network, where different schemes have been designed and a knowledge base has been generated» [8].

The development of applications for ubiquitous learning (u-learning) based on the general model of the system, its architecture as a set of software agents, a semantic network and ontologies are devoted to a study of the group of authors in [9]. The Ercan's, T. article is devoted to the use of mobile devices in e-learning systems, ontologies and a website with semantic functions. [10] «Mobile devices are mainly lack of regular user interfaces that facilitate the human-computer interaction and the access to network resources. However, almost all commercial applications contain their mobile versions. If we consider the importance of business and learning environments, there are still many new 
opportunities to integrate mobile devices with web-based services. Development of Educational Semantic Web and the implications for Web-based teaching and learning attracts great attention. This study focuses on creating a web site with semantic features taken from a student survey conducted to learn their e-learning awareness and developing an efficient search mechanism among mobile users in the learning environment. The ontology working in mobile devices benefits from adapting context and content information from a centralized system into a significant data mining application» [10].

The original architecture development for a personalized and adaptable e-learning system (APELS) using ontologies is presented by the authors Aeiad, E., Meziane, F. in [11]: «APELS aims to provide a personalised and adaptable learning environment to users from the freely available resources on the Web. An ontology was employed to model a specific learning subject and to extract the relevant learning resources from the Web based on a learner's model (the learners background, needs and learning styles). The APELS system uses natural language processing techniques to evaluate the content extracted from relevant resources against a set of learning outcomes as defined by standard curricula to enable the appropriate learning of the subject. An application in the computer science field is used to illustrate the working mechanisms of the APELS system and its evaluation based on the ACM/IEEE computing curriculum» [11].

Other studies are concerned with finding effective ways to measure the popularity of resources for e-learning systems. Of particular interest is the development of a group of authors [12], which presents the idea of modeling the assessment of resource popularity using the advantages of space-time localization in the educational area and includes managing the preliminary selection of resources with such localization to improve the efficiency of data access for end users. «A novel topic model is proposed to trace educational topics for the resultant spatial-temporal locality, and its practical construction method, based on an accelerated spectral algorithm and an ontology concept similarity metric, is also presented in the paper. With the proposed model, a light-weighted semantic inference approach is proposed to predict popular educational resources in the future data requests. Moreover, a systematic and efficient prefetching management mechanism working with replica techniques is suggested to support geo-dispersed cloud storage systems for educational applications» [12].
In the development of mobile learning technologies, developments related to the search for materials suitable for learning are useful. Thus, in [13], the authors propose to take advantage of the semantic web technologies by incorporating the semantic layer into the three-tier architecture of the classic web application. This level will contain three ontologies: the ontology of the learning context, the ontology of the learning object, and the ontology of learning design. «Most of the current e-learning platforms are based on a layered architecture which encapsulates the three levels of abstraction: data, application and presentation. The first layer is concerned with the storage of the data. The second handles the requests of the user interface by querying the storage media, after performing the various treatments and returning the results to the third layer this last layer then manages their display. These solutions are not sufficiently aware of the learner context. The context-awareness is highly recommended to deliver to the learner the learning material relevant to the current situation of the learner. To achieve this, we adopt the ontological approach to define a model to represent and manage context information. In this work, we want to perform a re-engineering of this architecture, with a view to incorporate the technology of the Semantic Web. To this end, we are proposing to insert a Semantic Layer between the layer of data and that of the application» [13].

Especially relevant in this study is data related to the type of mobile device in the learning process. «Retrieving the context information is not complete without taking in consideration the device type. It determines whether we talk about an e-learning experience or a m-learning one. The device mobility plays an important role to decide which learning experience will be delivered to the learner. Having a mobile device that has specific location and battery life will determine which the most suitable learning content to have. For example, if we are connected from a metro or public transportation, it will be suitable to have a learning content with a short duration because of the short time we spend in those places. The battery life of the device also should be taken in consideration, because the delivered learning materials should be in coherence with it. We can't have a long video course with a low battery life» [13]. The further developments of the same authors Bouihi, B., Bahaj, M. are very informative, related to the inclusion of a recommendation system in e-learning platforms 
to account for students of the past successful learning experience. «Nowadays, e-learning platforms are widely used in education for both universities and companies. Because learners are given the opportunity to access electronic learning courses through the network. This access allows developing learners' skills, while making the process of learning independent of time and place. However, the continuous development of e-learning platforms has led to a huge amount of learning materials available on the network. It is time-consuming for learners to find the learning materials that they really need. "The one size fits all" is no more working. The challenge is to deliver to the learners the right learning materials at the right time» [14]. As a result, the authors conclude that contextual recommendations allow you to learn successfully by providing the necessary training materials. «Context-aware applications play an important role in education, especially e-learning. Context recommendation systems give the opportunity to learners to lead a successful learning experience by getting the right learning materials that suit their needs at the right time. Semantic web technologies make these systems more performant and relevant. In this paper, we have proposed our semantic web architecture for current e-learning platforms. This ontology and rule based architecture is proposed to make use of ontology as a domain knowledge for gathering the learning context information and OWL Rules filtering as a recommendation technique» [14].

A number of studies and research articles are devoted to improving the effectiveness of existing learning management systems (LMS). In this regard, interesting recommendations are presented in [15] on adding adaptation and personalization to one of the most common open source learning management systems - Moodle.

Of greatest interest are the development of guidelines for the formation of recommendations based on ontologies [16]. In this case, the ontology is used to model and represent the subject area of knowledge about the student and learning resources, and the developed algorithms represent sequential learning patterns. «First, we have proposed a hybrid knowledge-based recommendation approach for recommending learning resources to the learners taking into account the ontology domain knowledge about the learner and learning resources as well as the learners' historical sequential learning patterns. Aggregation of this additional information into the recommender system will result in generation of recommendations that are more personalized to the learner. Secondly, in computing similarity of learners and generating predictions, ontology domain knowledge is considered alongside the ratings, hence improving the accuracy of predictions. Thirdly, the proposed hybrid knowledge-based approach addresses the cold-start problem by making use of available ontology domain knowledge arising from integration of ontology into the recommendation process. Additionally, it can alleviate sparsity problem by making use of the learner's sequential access patterns to predict learner's preferred learning resources in cases where their ratings are sparse. Lastly, our experimental results tested over a real world dataset demonstrate improved performance by our hybrid knowledge-based recommender system. Our recommendation approach can outperform those recommendation methods that do not incorporate ontology and learners' sequential learning patterns in their recommendation process» [16].

One of the tasks of research is the analysis and development of models and algorithms for searching and systematization, storage and analysis of information for the formation of individual educational trajectories and programs using ontologies. The process of achieving this goal is divided into several tasks:

Firstly, a domain model is needed to define the conceptual boundaries of the system being developed. The main documents necessary for the development of domain ontology are state and professional standards. Professional standards contain job descriptions and professional competencies of specialists, and also reflect the minimum necessary requirements for the profession from the point of view of employers.

Secondly, it is necessary to determine the necessary list of training courses and disciplines for the formation of the required competencies so that the work of the system is relevant.

Thirdly, you need to be able to understand which topics were covered by a discipline or training course, in order to identify the necessary sequence of their study.

Fourthly, it is necessary to build a recommendation system for the formation of educational trajectories, taking into account the order of training and the development of training courses.

An ontological approach is used to build a domain model. It is planned to use the created ontology to perform the function of a certain "framework" in certain professional areas in the field of information and communication technologies, which will describe the work functions, skills and knowledge, and knowledge that will play the role of key concepts.

One of the objectives of the research is to develop a method for selecting text documents that are necessary for organizing training on the selected competencies of the educational program. To solve it, it is necessary to create complex intelligent algorithms. Initially, the selection of terms that characterize a given area of 
scientific knowledge is carried out, and the second is the construction of the ontology of a knowledge base area using these terms. There are standard approaches for extracting key phrases from individual documents based on specific metrics.

The subject of the research is the working curriculum, which is defined as a set of data describing the learning outcomes and the content of the discipline (course). Such information includes the goals and objectives of training, the results of the study of the discipline or training course, which include relevant knowledge and skills.

To determine the relationship between learning outcomes (acquired competencies) and disciplines (training courses) through appropriate consequences it is proposed to use the method based on the analysis of formal concepts. This method allows for conceptual clustering and finding the similarity of an arbitrary set of objects. To establish a connection between objects and their properties, a formal context is used, which is reflected by the three of the set $\mathrm{K}$ the set of objects $\mathrm{G}$ (course content), the set of properties $\mathrm{M}$ (competencies), and the connection I between objects and properties GxM. In this case, the search is considered and implemented for the construction of associative rules classification, i.e. for grouping objects in accordance with their common features.

When using the analysis of formal concepts for the construction of ontology, it is supposed to build the basis of ontology - the lattice of formal concepts, i.e. the derivation of the set of concepts of the domain and the identification of the object-property relationship given on the set. Application of the analysis of formal concepts allows you to identify taxonomic relationships between concepts, building formal concepts. The disadvantage is that the source data for this method is a formal context, which is built by an expert. It is necessary to create a model for automatic constructing a lattice of formal concepts without the involvement of experts through methods of identifying the similarity of texts, in our case, the texts include the object of study and the source data.

Methods for analyzing formal concepts are used to extract key phrases from a document, and without using external information based on an analysis of the content of the document.

\section{RESUlts}

At present, competences designed as professional abstractions of human behavior are of fundamental importance in the management of workers' knowledge and skills in many areas. In human resource management (HRM), competencies can be a criterion for choosing people to perform certain tasks. Competency-based selection allows you to determine compliance and increase productivity within the enterprise.

By creating a competency map for each employee, it is possible to build an effective human resource management system. Such a map helps in vertical and horizontal career development. The motivation of the employee determines the interest in development, that is, learning. The objectives of training are formed directly on the basis of the set of competencies that an employee needs to acquire to move up the career ladder.При использовании компетенций формируются следующие правила:

1. One competency can be a combination of other competencies: it allows you to reuse competencies to create new ones.

2. Competences belong to a certain level. Hierarchical representation of competencies - allows you to adjust the relationship of dependencies between competencies

3. Competence is decomposed into elements: knowledge, skills, psychological attitude (including behavior, personal characteristics, environment), purpose of application, task of application.

4. The division into levels of competence - necessary for assessing the competence of an employee, recruiting staff or training program, is a guideline for assessing gaps in knowledge and skills.

5. The level of competence of the elements of competence: allows you to better assess and maintain the processes of learning, evaluation or recruiting

6. Competences belong to a certain type, it gives a special character to the use of competence.

7. Motivation. Any employee has a motive for acquiring competence (new position, new field of activity, testing of knowledge, etc.).

The motive to possess the appropriate competence can be attributed to the purpose of the application and objectives of the application. These additional elements will improve the accuracy of the result, narrowing the scope of a particular competence. The increase in the number of elements in the competence implies an increase in accuracy in assessing the effectiveness of training. For example, the competence of "Analysis and Decision Skills" can be narrowed down to "Skills of analyzing and making decisions on insured events". Concretization of the situation for which the competence is formed, reduces the duration of training. A person excludes an option in which in the process of learning he encounters knowledge already known to him and can be trained to solve a specific problem if he only has difficulties with it. The purpose of the application sets the context in which the competence is used.

The main element of which is a competency model - a model based on ontology. It represents all key aspects of competency management. The main advantage of the ontological approach is a holistic approach to managing and automating the process of e-learning. There are many interesting studies and publications in this area, for example $[4,5]$. At the same time the following important indicators are achieved: consistency, complexity, uniformity, scientific character, reuse - repeated and repeated use of educational materials. Such a model can be used in matters of employment, movement of employees on the career ladder, changes in professional skills, obtaining a new position, etc. (knowledge). It is also important to complete this classification with elements related to the person's behavioral characteristics,

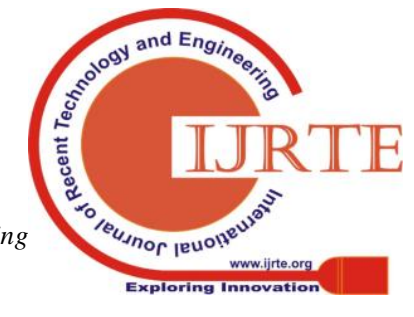


personal qualities for a full understanding of the professional situations in which it can be used.

The employee has a strong motivation to take a course. His motive determines the set of competencies that he would like to receive. The motive also determines the position if the employee wants to change skills or get promoted through the career ladder to a managerial position. Motive and position or, in other words, the role played by the employee in the company, determine the purpose of training. Knowing how to play a professional role means gaining certain competencies related to that role. These same competencies are determined by the motivation of the employee to learn.

The purpose of training includes a set of competencies that have been determined by the motive and affect the formulation of the learning task. An employee has certain conditions for training (remotely, in practice, at work, in the evening, in the morning, etc.). Thus, learning conditions, learning tasks and previous education determine the learning model. Initially, the employee also has a certain number of competencies and a certain psychological attitude, which affects the ability to obtain new competencies. The above elements are depicted in Fig. 1, which presents a general model of the ontology of professional competencies.

The main static elements in the model are the position, competence and its elements. Position means professional profile, it can set the requirements of certain competencies or directly its elements. The presented competency model allows you to divide competences into elements or combine them into a complex composite object. The ontological approach allows you to create all possible options and link them with real, specific experience of people.

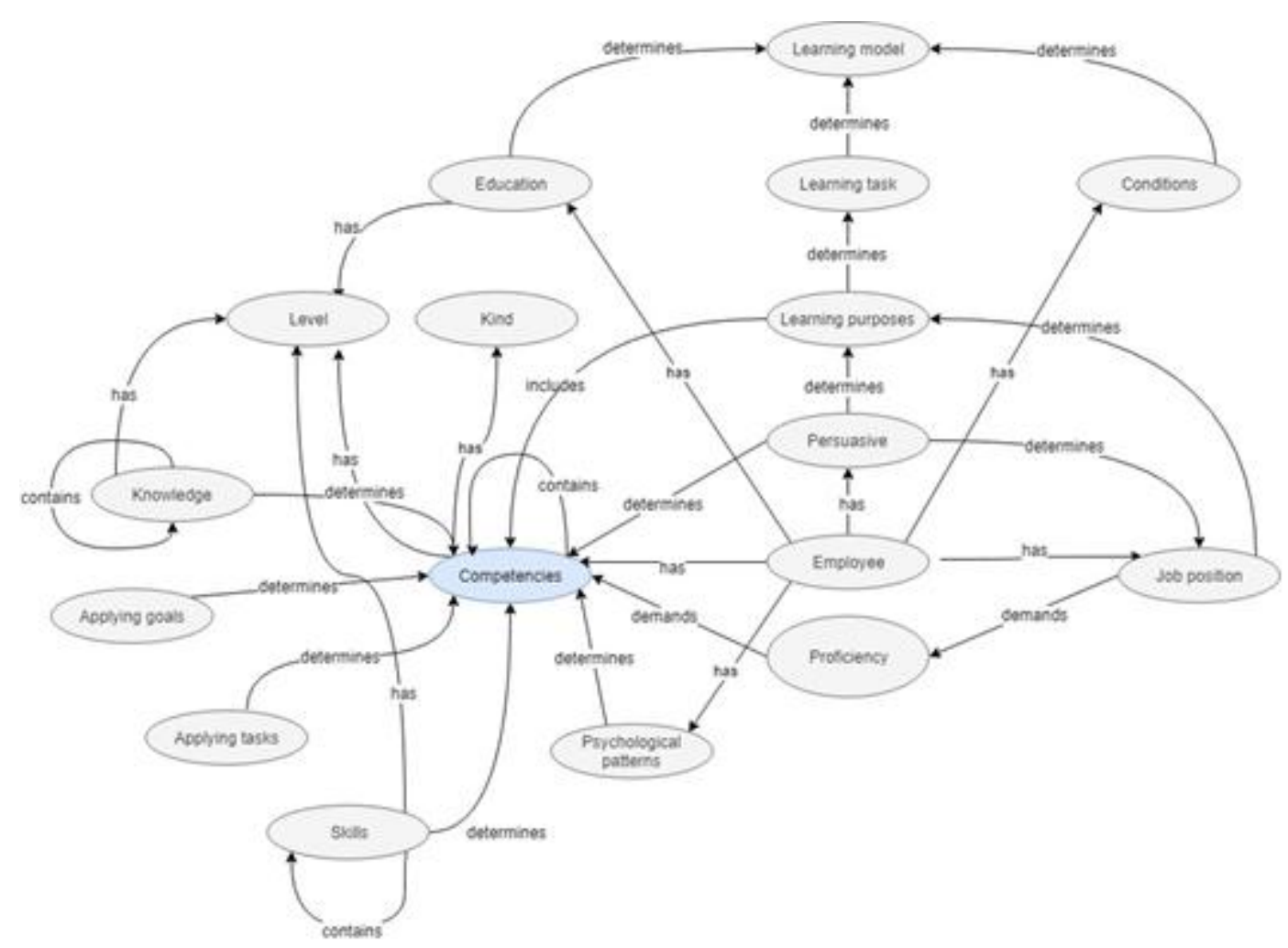

Fig. 1. Competence Model

In the proposed model, the purpose of using the elements "Purpose of application" and "Task of application" are different. In particular, they may define the context in which the competency was applied or should be applied. In other words, they are a collection of information about the situation in which a particular competency should be applied. This means that a person who has applied for a certain professional role may have the necessary competence, but cannot be hired, because this competence is used for specific purposes or for solving a specific task that are not compatible with the required or partially compatible. Then it is necessary to raise the level of competence or choose the one that has a wider scope of its application, or vice versa, narrow specialization. Since the elements of competence are static, from the goals and objectives of the application you can collect various situational options for the use of competence.
Our research and the results obtained in this area are presented in a number of published articles [17-23].

The proposed model provides numerous possibilities for deducing facts that are not clearly represented in the knowledge base and which can be derived by using reasoning based on both ontology and reasoning rules. The competency model is also an integral part of adaptive and personalized learning. Such training takes place on the basis of a recommendation system. And one of the first stages of building the architecture of the recommendation system is in the history of training, the user profile, the competences he possesses, the interests of the user, his motivation and learning objectives. The system of recommendations is a phased definition of the necessary conditions for employee training. The history 
of training shows the general specialization of the employee, determines the knowledge and skills that he already has as a result of previous training. But many skills are acquired in the process of work, professional development, therefore, a set of competencies that an employee already possesses is taken into account. The employee's interest and motive determine what competencies and skills he lacks for further work in the area of his interest. The learning style and user profile define the possible learning conditions. All these initial and crucial recommendations are combined and, based on keywords and similarity of parameters, definitions, which the employee already knows, determine possible courses of study. As mentioned above, the goal of learning includes the need to gain new competencies and determine the further learning path. The competency model should be integrated into the system of personalized corporate e-learning based on mobile technologies [24-29].

Web application development for corporate e-learning system and staff adaptation

The following technologies have been chosen as the technological stack of the server part (API) of the system:

- Python programming language (version 3.7).

- Django framework (version 1.12).

- Django Rest framework.

The choice in favor of these technologies was made because of the convenience and suitability of these tools for corporate training tasks. Django is a free framework for developing mobile applications, containing many ready-made solutions, and also convenient for developing new components for the server part of this system. Django Rest framework - a convenient and flexible set of tools for creating an API. The system itself includes:

- A set of models representing database entities.

- Data serialization.

- Display and transfer of data (View).

The user table (user) is a standard user implementation in Django and is not subject to change. The main elements of the database:

- Training course.

- Training module.

- The element of competence of the trained employee (knowledge, skills, abilities).

- Employee

In addition, there are additional entities in the database that are necessary for the system:

- Module content.

- Direction.

- Test.

- Practical task.

An API exists for transferring data between an Android application and a database. The query architecture is based on the database (Fig.2)

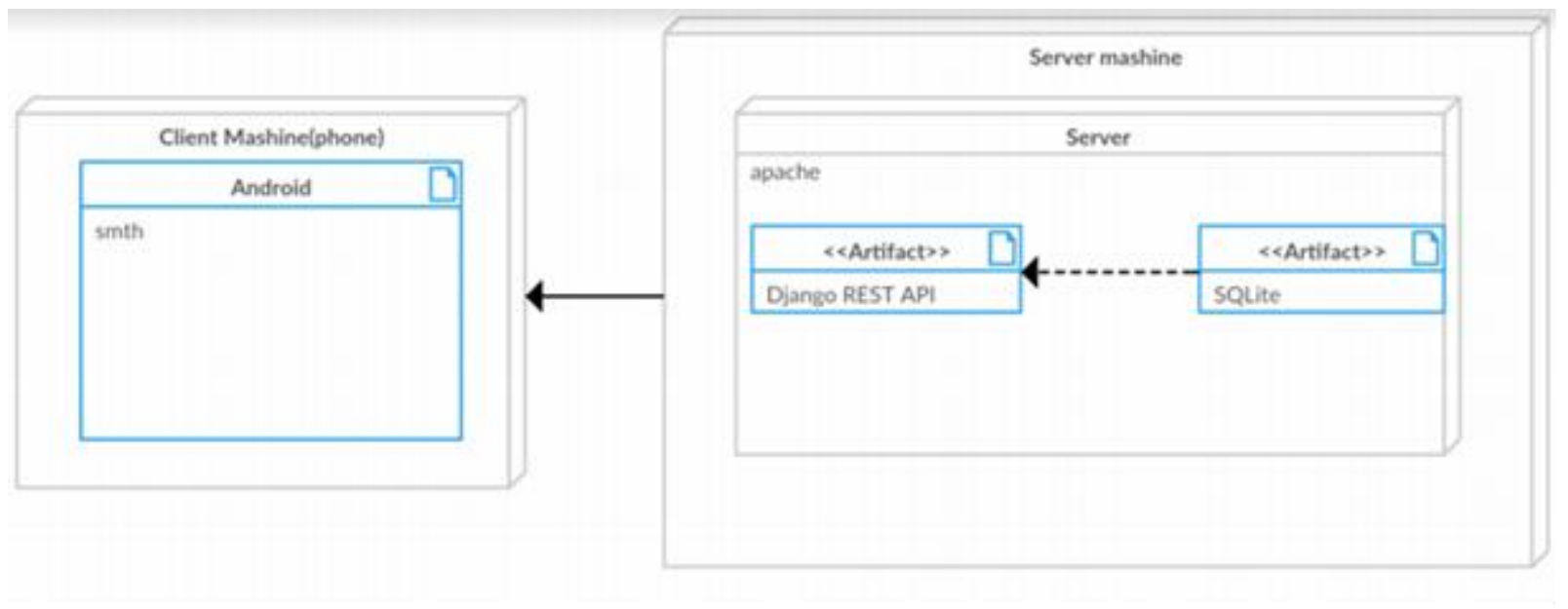

Fig. 2. Query Architecture

It is based on the architectural style REST and all requests and server responses are designed in accordance with REST. This means that in this case the service is a simple information management interface without additional internal layers. Data is obtained by accessing a unique identifier, which is the URL. The main advantage of using the REST approach is in the convenience of interacting with various client options. Accordingly, to expand the number of clients by creating a web version, as well as clients for other platforms will not be a problem, without affecting the ready-made blocks of the system.

The client application (Android client) displays the data, as well as implements part of the functionality provided by the API. The product is a ready-made file with the .apk extension installed on the smartphone. The application has API level 21, i.e. it is supported by all smartphones on the Android platform not older than Android 5.0, which allows reaching approximately $88.9 \%$ of the audience of Android smartphones.

Network client interaction with the server is implemented using the library Retrofit2, which is great for the REST API and encapsulates all the subtleties of working with the network, allowing you to focus on processing and presenting the data sent or received. Mobile client capabilities are shown in the diagram (Fig. 3)

Published By:

Blue Eyes Intelligence Engineering 


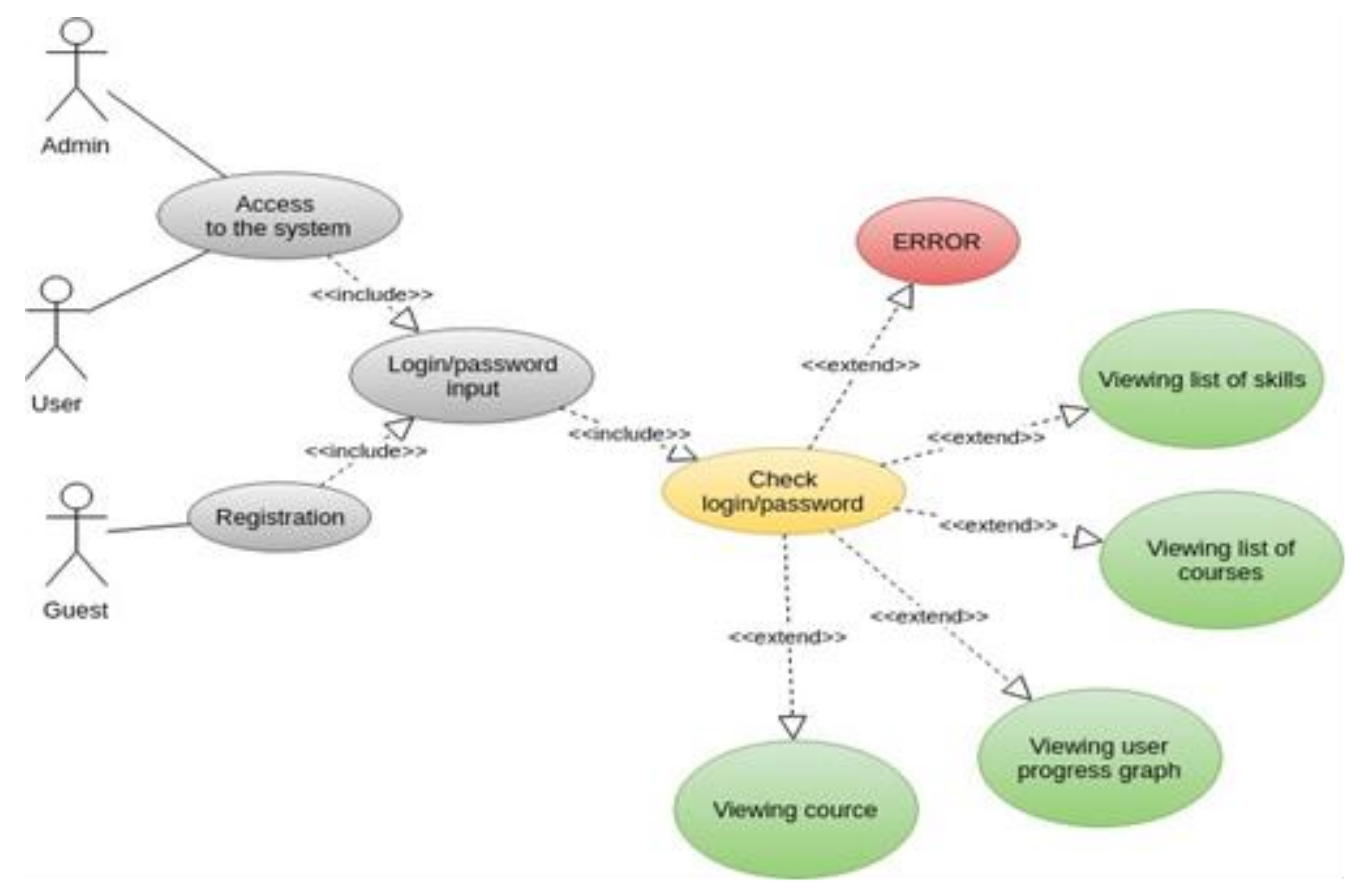

Fig. 3. Use-case of the mobile application

The operation of the application screens (user interfaces) and their interactions are presented in the diagram (Fig. 4):

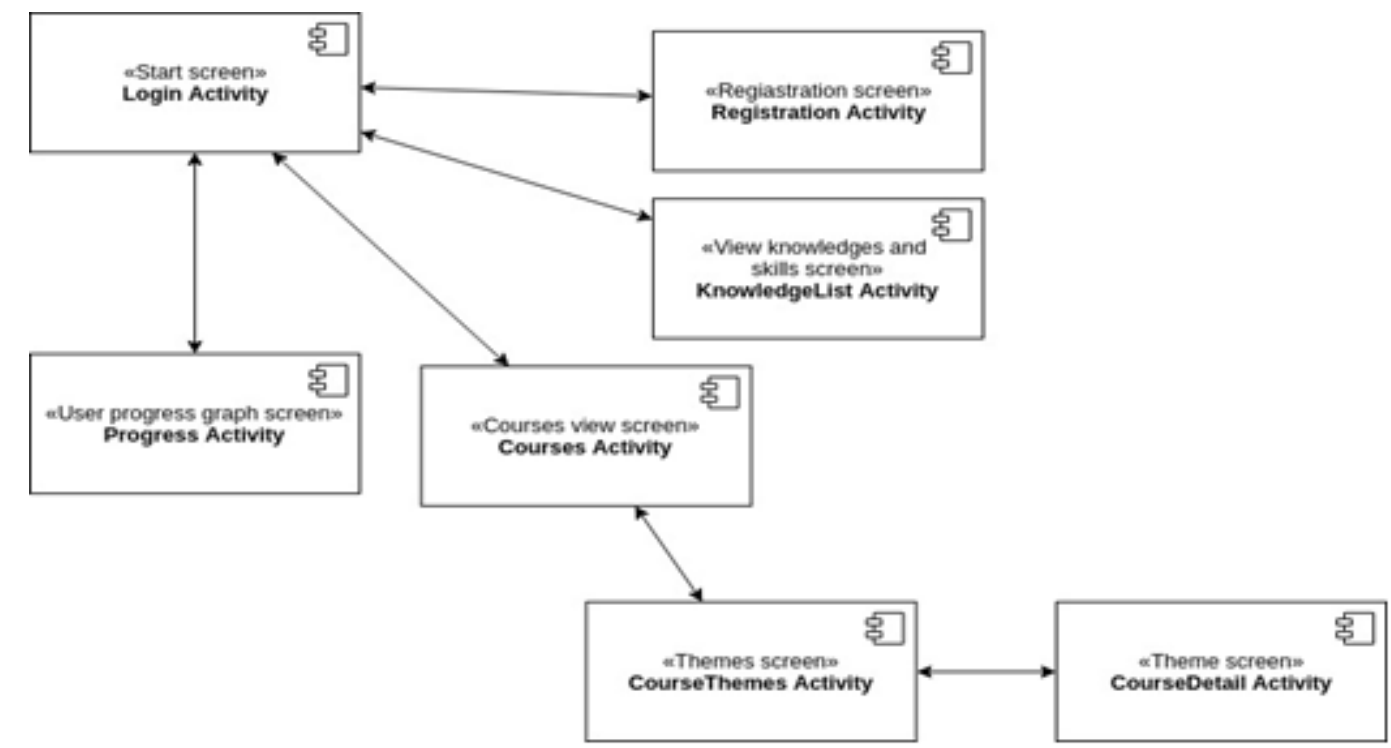

Fig. 4. Graph of transitions between screens (user interfaces)

The overall architecture of the mobile application is presented in the diagram (Fig. 5) 


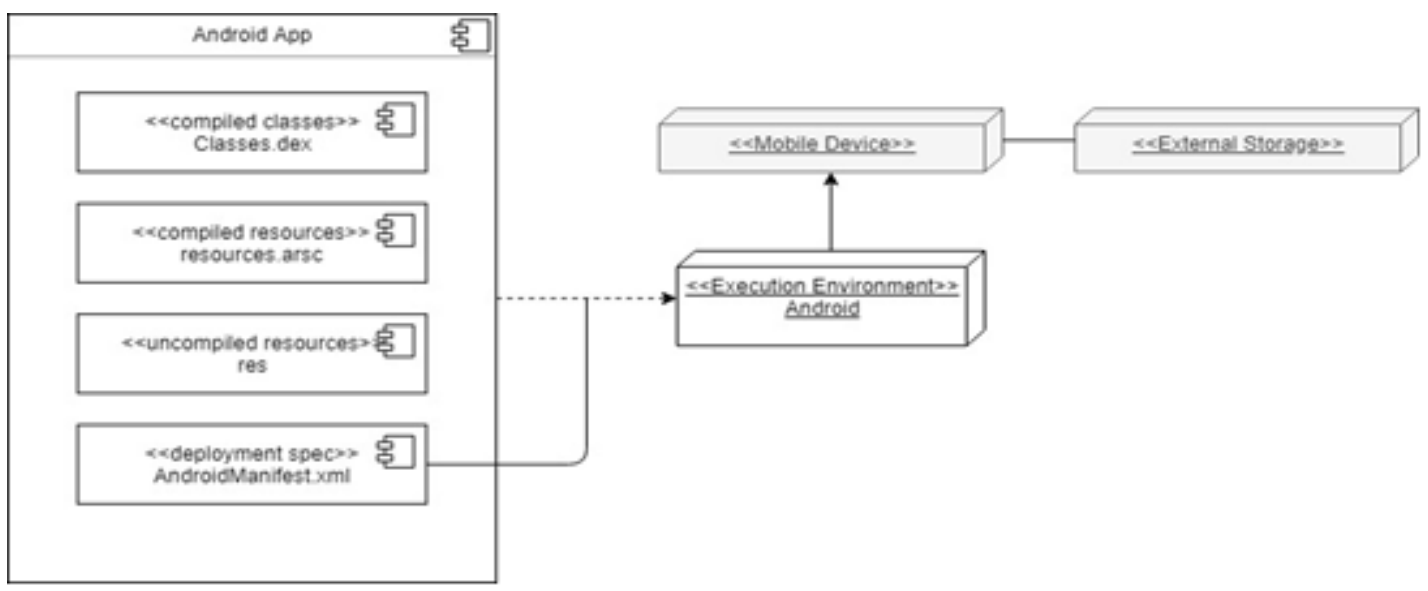

Fig. 5. General Application Architecture

The application has an implementation presented in the form of a class map (Fig. 6):

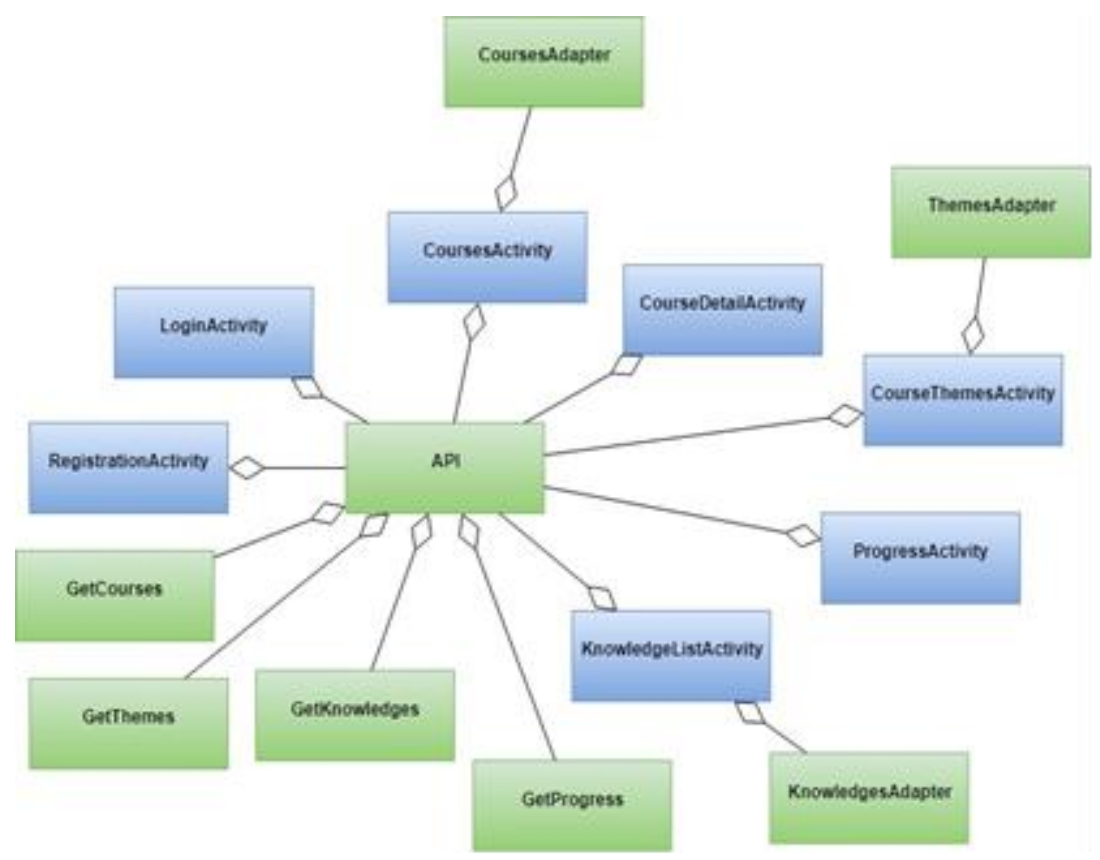

Fig. 6. Class Map

On the basis of pre-developed solutions and the trajectory of individual training, a set of courses, classes, documents assigned for an employee of the enterprise in the process of training or advanced training is selected. The application provides access to various training materials at any time, which allows training in any convenient place and at any time. The system allows, on the basis of the required list of materials submitted to the study, to obtain additional knowledge, and also allows you to quickly determine the level of learning material on the basis of tests and practical tasks, information about which can also be obtained in the mobile application.

\section{CONCLUSIONS AND RECOMMENDATIONS}

Thus, the problem of high staff turnover has a direct correlation with the built program of adaptation and personnel training. Automation of this process through the development and implementation of management information systems, staff training and development significantly reduces the time spent by experienced staff on introducing the course of work, features of solving professional tasks and organizational processes of the company, thereby reducing the cost of implementing the adaptation process. The use of ontologies makes this process convenient for visualization and automation in the formation of individual adaptation programs and employee training. And the use of the developed mobile application makes the process of corporate learning comfortable and accessible to staff on training time and mobile devices. Personalization in the framework of the implementation of this system makes is possible to increase the rate of involvement and motivation of new employees in the adaptation process, reduce the time of entry of new employees in real projects, and can also work as an image element of the company.

The implemented system based on the mobile application allows you to take 
educational courses on individual trajectories and adaptation plans at a convenient time, as well as to evaluate the absorption of materials by testing and performing various practical tasks in remote mode. Further research is aimed at solving the problem of ensuring motivation and employees' engagement in the process of learning, adaptation and development.

\section{REFERENCES}

1. Kobtseva M.I. The use of modern innovative technologies in the management of labor adaptation of staff // "Economy and Society" 2017. №2 (33). C. 22.

2. V. Campbell, W. Hirsh Talent Management System: A Four Step Approach

URL:https://www.employment-studies.co.uk/system/files/resources/files 1502.pdf

3. M. Smatana and P. Butka Extraction of Keyphrases from Single Document Based on Hierarchical Concepts (SAMI 2016, IEEE 14th International Symposium on Applied Machine Intelligence and Informatics, January 21-23, 2016, Herl'any, Slovakia, p.93-98).

4. Tarus, John K.; Niu, Zhendong; Mustafa, Ghulam Knowledge-based recommendation: a review of ontology-based recommender systems for e-learning / ARTIFICIAL INTELLIGENCE REVIEW T. 50 / 1. pp. 21-48. https://link.springer.com/article/10.1007\%2Fs10462-017-9539-5

5. Berniukevicius, Andrius On application of semantic web technologies to personalise learning / 12th International Technology, Education and Development Conference Valencia, SPAIN, MAR 05-07, 2018, INTED Proceedings pp.4281-4288.

6. Abech, Marcia; da Costa, Cristiano Andre; Victoria Barbosa, Jorge Luis. A model for learning objects adaptation in light of mobile and context-aware computing / PERSONAL AND UBIQUITOUS COMPUTING T. 20 № 2 .SI p. 167-184.

7. Ingavelez-Guerra, P., Robles-Bykbaev, V., Oton, S., Vera-Rea, P., Galan-Men, J., Ulloa-Amaya, M., Hilera, J.R. A proposal based on knowledge modeling and ontologies to support the accessibility evaluation process of learning objects(Conference Paper) / Congreso Argentino de Ciencias de la Informatica y Desarrollos de Investigacion, CACIDI 201819 December 2018, № 85843552018 Congreso Argentino de Ciencias de la Informatica y Desarrollos de Investigacion, CACIDI 2018; Buenos Aires; Argentina; 28 November 2018 до 30 November 2018; CFP18H47-ART.

8. Abech, M., da Costa, C.A., Barbosa, J.L.V., Rigo, S.J., da Rosa Righi, R. 3rd International Conference on Advances in New Technologies, Interactive Interfaces and Communicability, ADNTIIC 2012: Design, E-Commerce, E-Learning, E-Health, E-Tourism, Web 2.0 and Web 3.02012, 12p3rd International Conference on Advances in New Technologies, Interactive Interfaces and Communicability: Design, E-Commerce, E-Learning, E-Health, E-Tourism, Web 2.0 and Web 3.0, ADNTIIC 2012; Huerta Grande, Cordoba; Argentina; 3 December 2012 до 5 December 2012.

9. Duran, E.B., Alvarez, M.M., Unzaga, S.I. Generic model of a multi-agent system to assist ubiquitous learning / Procedia - Social and Behaviora Sciences Volume 28, 2011, Pages 963-967World Conference on Educational Technology Researches, WCETR-2011; Nicosia/Kyrenia; Cyprus; 5 July 2011 до 9 July 2011.

10. Ercan, T. Benefits of semantic approach in the learning environment / Procedia - Social and Behavioral Sciences 28 (2011) 963 - 967.

11. Aeiad, E., Meziane, F. An adaptable and personalised E-learning system applied to computer science Programmes design / Education and Information Technologies Volume 24, Issue 2, 16 March 2019, p/ 1485-1509.

12. Huang, Q., Huang, C., Huang, J., Fujita, H. Adaptive resource prefetching with spatial-temporal and topic information for educational cloud storage systems / Knowledge-Based Systems 2019.

13. Bouihi, B., Bahaj, M. An ontology-based architecture for context recommendation system in E-learning and mobile-learning applications Proceedings of 2017 International Conference on Electrical and Information Technologies, ICEIT 2017, p. 1-6.

14. Bouihi, B., Bahaj, M. A Semantic Web Architecture for Context Recommendation System in E-learning Applications / Lecture Notes in Networks and Systems 37, p. 67-73.

15. Saleh, M., Salama, R.M. Recommendations for building adaptive cognition-based e-Learning / International Journal of Advanced Computer Science and Applications Volume 9, Issue 8, 2018, P. 385-393.
16. Tarus, J.K., Niu, Z., Yousif, A. A hybrid knowledge-based recommender system for e-learning based on ontology and sequential pattern mining / Future Generation Computer Systems 72, c. 37-48.

17. Bakanova A., Nikitina L.N., Shikov P.A., Shikov U.A., Shikov A.N. Recommended system of personalized corporate e-learning based on ontologies / MATEC Web of Conferences, Vol. 193, 05074, (2018).

18. Chunaev A.V., Shikov A.N. The method of personalized corporate e-learning based on personal traits of employees / Procedia Computer Science Vol. 136, 2018, Pages 511-521.

19. Bakanova A., Chunaev A.V., Loginov K.V., Okulov S.A., Shikov A.N. / Mobile technologies as innovations in corporate e-learning systems // Scientific journal "labor Economics» -2018. Tom 5. № $2 . \quad$ doi: 10.18334/et.5.2.39096

20. Bakanova A., Chunaev A.V., Loginov K.V., Okulov S.A., Shikov A.N. The concept of personalized e-learning with the use of mobile applications based on ontologies / Ponte - 2018, Vol. 74, No. 1|SI, pp. 61-70.

21. Rahideh M, Mazloum SZ. Combination System Optimization of Solar Collector/ Photovoltaic with Genetic Algorithms. Medbiotech Journal. 2019;03(02):58-64.

22. Kashisaz S, Mobarak E. The Effects of Private Education Institutes in Providing Modern Financial Knowledge in Developing Countries. Journal of Humanities Insights. 2018;02(04):172-8.

23. Kheirabadi MA, Mirzaei Z. Descriptive valuation pattern in education and training system: a mixed study. Journal of Humanities Insights. 2019;3(01):7-12.

24. Eslami R, Ahmadi S. Investigating the Role of Educational Media on Secondary School Students' Learning Process Improvement in Jahrom City. Journal of Humanities Insights. 2019;3(01):13-6.

25. Mirrashid N, RakhtAla SM. Fuel Cell Systems and Developments in Control Abilities. Medbiotech Journal. 2019;03(02):41-6.

26. Vajravelu, K. (2018). Innovative Strategies for Learning and Teaching of Large Differential Equations Classes. International Electronic Journal of Mathematics $\quad$ Education, 13(2), 91-95. https://doi.org/10.12973/iejme/2699

27. Kurmanali, A., Suiyerkul, B., Aitmukhametova, K., Turumbetova, Z., \& Smanova, B. (2018). Analysis of the proverbs related to the lexemes" tongue/language". Opción, 34(85-2), 97-115.

28. Ganjali, M., \& Teimourpour, B. (2016). Identify Valuable Customers of Taavon Insurance in Field of Life Insurance with Data Mining Approach. UCT Journal of Research in Science, Engineering and Technology, 4(1), 1-10.

29. Fujo, M. H., \& Dida, M. A. (2019). Centralized Admission System for Advanced Level Private Schools: Case of Kilimanjaro Region, Tanzania. Journal of Information Systems Engineering \& Management, 4(1).

\section{AUTHORS PROFILE}

Bakanova A., Postgraduate, ITMO University, Saint Petersburg, Russia.

Letov N.E., Master's Degree, ITMO University, Saint Petersburg, Russia.

Kaibassova D., Postgraduate, Eurasian National University L N Gumilev (ENU), Astana, Kazakhstan.

Kuzmin K.S., Master's Degree, ITMO University, Saint Petersburg, Russia,

Loginov K.V., postgraduate, ITMO University, Saint Petersburg, Russia,

Shikov A.N., Candidate of Engineering Sciences, Associate Professor, ITMO University, Saint Petersburg, Russia 